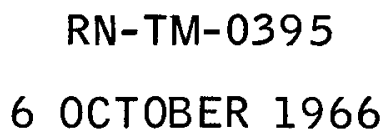

\title{
PRELIMINARY SHIELDING ANALYSIS FOR THE \\ FAST FLUX TEST FACILITY
}

|DIstribution of THIS DOCUMENT UNLIMITED 


\section{DISCLAIMER}

This report was prepared as an account of work sponsored by an agency of the United States Government. Neither the United States Government nor any agency Thereof, nor any of their employees, makes any warranty, express or implied, or assumes any legal liability or responsibility for the accuracy, completeness, or usefulness of any information, apparatus, product, or process disclosed, or represents that its use would not infringe privately owned rights. Reference herein to any specific commercial product, process, or service by trade name, trademark, manufacturer, or otherwise does not necessarily constitute or imply its endorsement, recommendation, or favoring by the United States Government or any agency thereof. The views and opinions of authors expressed herein do not necessarily state or reflect those of the United States Government or any agency thereof. 


\section{DISCLAIMER}

Portions of this document may be illegible in electronic image products. Images are produced from the best available original document. 
RN-TM-0395

6 October 1966

\author{
Preliminary Shielding Analysis \\ for the \\ Fast Flux Test Facility
}

This report was prepared as an account of work sponsored by the United States Government. Neither the United States nor the United States Energy Research and Development Administration, nor any of their employees, nor any of their contractors, subcontractors, or their employees, makes any warranty, express or implied, or assumes any legal liability or responsibility for the accuracy, completeness or usefulness of any information, apparatus, product or process disclosed, or represents that its use would not infringe privately owned rights.
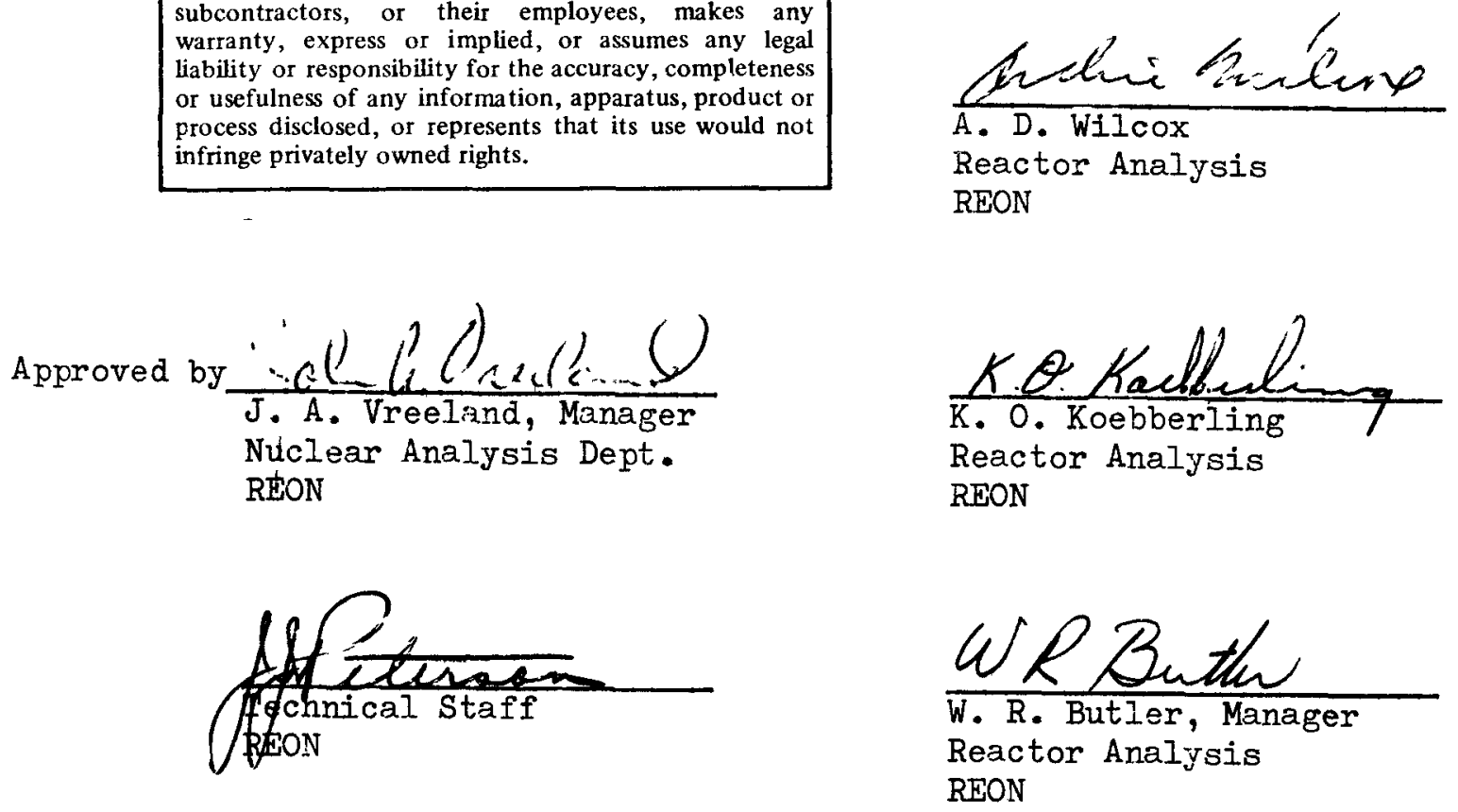
Abstract $\ldots \ldots \ldots \ldots \ldots \ldots \ldots \ldots \ldots \ldots \ldots \ldots \ldots \ldots \ldots \ldots \ldots \ldots$

List of Figures ........................ ii

List of Tables ........................ ii

List of References ..................................

I. INTRODUCTION .......................... I 1

II. DESCRIPTION OF THE FFTF SHIELDING PROBLEM ....... 2

III. ANALYSIS $\ldots \ldots \ldots \ldots \ldots \ldots \ldots \ldots \ldots \ldots \ldots \ldots \ldots \ldots \ldots \ldots \ldots \ldots \ldots$

A. Computer Codes ....................... 5

B. Analytical Models ...................... ?

C. Radiation Source Terms .................. ?

D. Nuclear Data........................ 17

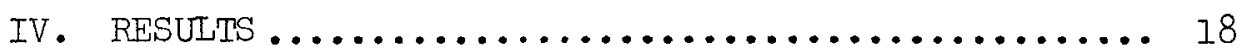

A. Full Power.......................... 18

B. Shutdown ........................... 25

V. CONCLUSION ............................... 28 


\section{ABSTRACT}

A preliminary analysis of the FFTF shielding problems has been completed. Both full power and shutdown conditions were considered to identify the shielding requirements imposed by specified access criteria.

The case of a single "stuck-fuel element" is the controlling criterion for the top rotating shield. The required thickness was found to be 12-inches of steel followed by a portable 4-inch thick lead shield. Neutron leakage is the dominant contributor to the dose rate above the top rotating shield during full power operation. The required attenuation can be achieved by a number of alternative shield configurations. Some preliminary configurations include: (1) 30-inches of borated graphite with polyethelene plugs placed either in the reactor top shield or in the process shield in any desired comnination, (2) 35-inches of borated graphite with borated graphite plugs placed as described above, and (3) 39-inches of borated graphite with sodium plugs placed as described above.

The amount of lead shielding required around the fuel handing machine was found to be 10.6 inches. 


\section{LIST OF FIGURES}

\begin{tabular}{|c|c|c|}
\hline I. & Sketch of the Proposed Arrangement for FFTF & 3 \\
\hline 2 . & Analytical Model for the FHTF & 8 \\
\hline $3 \cdot$ & Normalized Time Variation of Fission Product Activity & 12 \\
\hline 4. & Radial Distribution of Fast Neutron Flux & 19 \\
\hline $5 \cdot$ & Radial Distribution of Gamma Ray Dose Rate & 20 \\
\hline 6. & Axial Distribution of Fast Neutron Flux - Graphite Plugs & 21 \\
\hline 7. & Axial Distribution of Fast Neutron Flux - Polyethelene Plugs & 23 \\
\hline 8. & Axial Distribution of Fast Neutron Flux - QAD with C-Moments Data & 24 \\
\hline 9. & Neutron Spectra at Three Axial Locations & 26 \\
\hline 10. & Axial Distributions of Gamma Ray Dose Rates - Unshielded & 29 \\
\hline 11. & Dose Rates Above the Top Rotating Shield for the "Stuck-Fuel" Case & 30 \\
\hline 12 . & Neutron Induced Activity of the Steel Pipe Chase & 31 \\
\hline 13 . & Gamma Dose Rate Distribution Through the Fuel Handling Machine & 32 \\
\hline
\end{tabular}




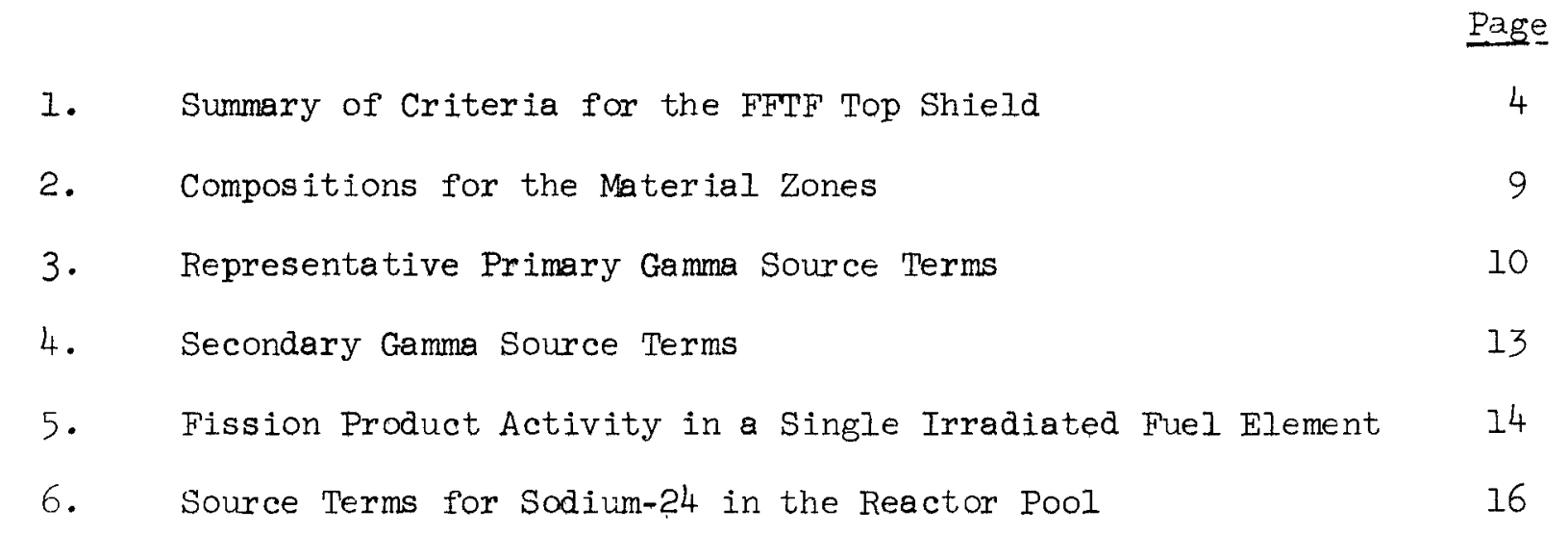


1. Fast Flux Test Facility - Interim Reference Concept, BNWL-CC-400, February 1, 1966.

2. FFTF Proposed Reactor Arrangement, Idaho Nuclear Corporation, Drawing Number 340066, September 8, 1966.

3. The DSN and TDC Neutron Transport Codes, B. Carlson, C. Lee, J. Worlton, LAMS-2255, February 12, 1960.

4. The DTK and DDK Neutron Transport Theory Codes, W. J. Worlton (IASI), Private Communication.

5. The QAD-P5 Code - A Neutron and Gamma Ray Shielding Code, R. Malenfant (LASL), Private Communication.

6. K. 0. Koebberling, et. al., Lockheed Fission Product Inventory Code, ER-6906, May 1964.

7. Special FFTF Shielding Studies, BNWL-CC-175, Volume 3, August, 1965

8. Activation Source Strength Program - ACT - II, P. C. Heiser and L. 0. Ricks, WANL-TNR-063, Addendum 1, September, 1962.

9. Reactor Handbook, Vol. III (Part B), Edited by E. P. Blizzard, New York: Interscience Publishers, 1962.

10. Six and Sixteen Group Cross Sections for Fast and Intermediate Critical Assemblies, G. E. Hansen, W. H. Roach, LAMS-2543, 6 December 1961.

11. Goldstein, H., Fundamental Aspects of Reactor Shielding, (Reading, Mass: Addison-Wesley Publishing Co. Inc., 1959) 


\section{INTRODUCTION}

Shielding analyses were performed on the Fast Flux Test Facility $\left(\right.$ FFTF $^{(1)}$ ) for the Idaho Nuclear Corporation (INC). The FFTF reactor concept is $\mathrm{PuO}_{2}$ fueled, sodium cooled, and unmoderated with a thermal power of $400 \mathrm{MW}$. Its design objective is to provide fast neutron irradiation fluxes of about $1 \times 10^{16} \mathrm{n} / \mathrm{cm}^{2}-\mathrm{sec}$ for 17 -day periods.

This report conveys the results of some preliminary shielding analyses that provide a survey of the FFTF shielding problems. In addition, preliminary specifications are developed for the various radiation shields. On the basis of the access criteria selected for this study, the material and thickness specifications for the biological shields are summarized below.

\begin{tabular}{|l|l|l|}
\hline \multicolumn{1}{|c|}{ Summary of Preliminary Shield Specifications } \\
\hline Shield Name & Material & Thickness \\
\hline Sodium Pool & Sodium \& Steel & $15 \frac{1}{2}$ feet \\
Reactor Top & $\begin{array}{l}\text { Borated graphite } \\
\text { W/o plugs }\end{array}$ & 20 inches \\
Prield & $\begin{array}{l}\text { Borated graphite } \\
\text { w/o plugs } \\
\text { Steel }\left(12^{\prime \prime}\right) \text { plus } \\
\text { Lead }\left(4^{\prime \prime}\right)\end{array}$ & 19 inches \\
\hline Rotating Shield & 16 inches \\
\hline
\end{tabular}

The 4-inches of lead specified for the rotating shield may be a portable shield that is to be used only for personnel access during a "stuckfuel" incident.

\footnotetext{
(1) This and subsequent superscripts identify references given in the Iist of References
} 


\section{DESCRIPTION OF THE FFTF SHIELDING PROBIEM}

A sketch of a proposed arrangement for the FFTF is shown in
Figure 1. (2) Note the provisions for a top rotating shield (with portable lead segment), a process shield, and a reactor top shield. Note also that the sodium level in the pool is 15.5 feet above the fueled core.

The shielding problem is the prediction of the radiation distributions about the FFTF that result from all significant radiation sources during full power as well as following shutdown. Comparison of these radiation distributions with the shield criteria summarized in Table I form the basis for a preliminary selection of shield materials as well as shield thicknesses.

Note that all the criteria are specifications on radiation leakage in the upward direction, Although some analyses were performed for the radial distributions of leakage radiation, the principal effort was directed at defining the axial distributions above the fueled core. 
FIGURE I

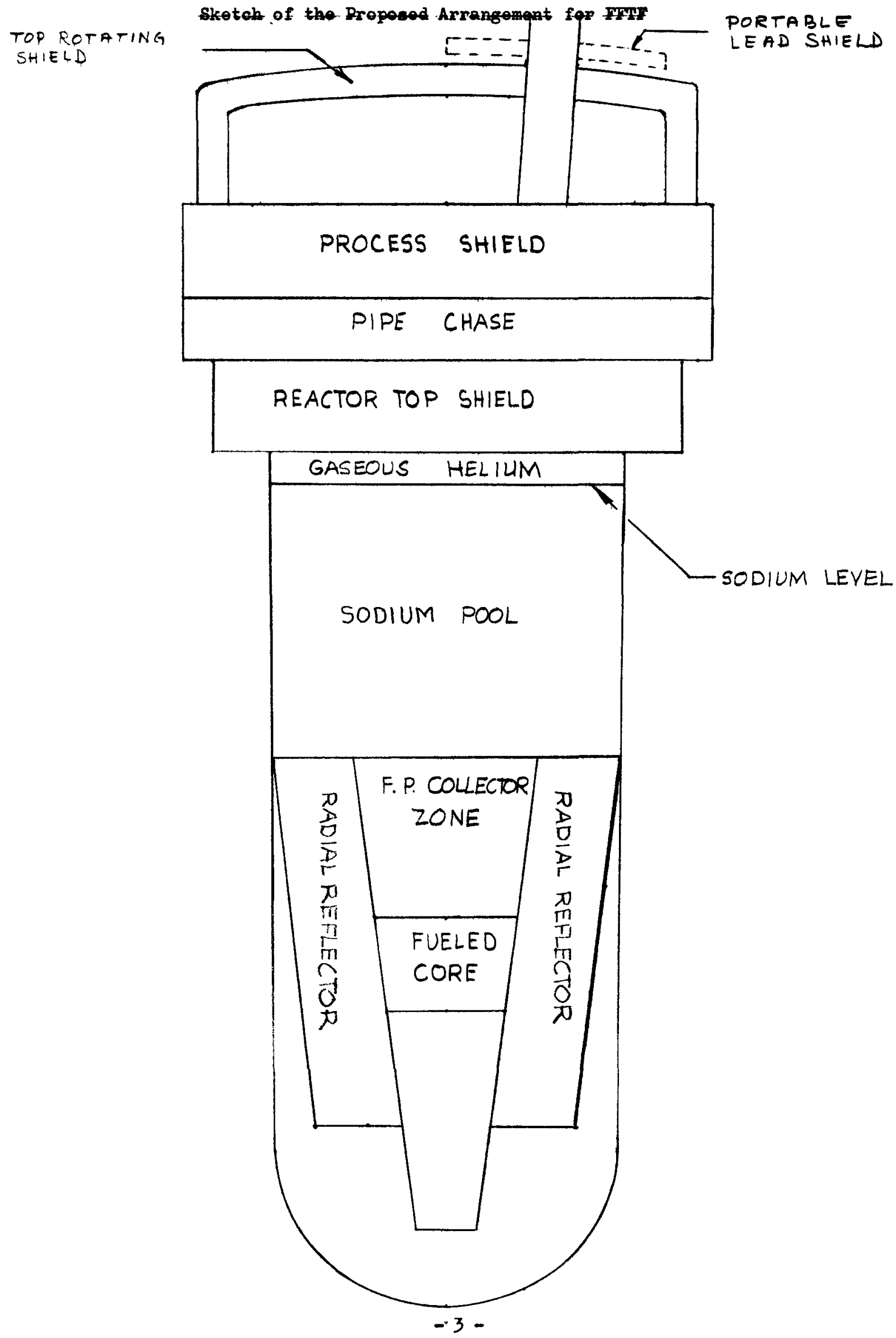


TABLE I

Summary of Criteria for the FFTF Top Shields

\section{Full Power}

A. Dose Rates 3-feet above Rotating Shield

1. For unlimited access: $2 \frac{1}{2} \mathrm{mr} / \mathrm{hr}$

2. For restricted access: $100 \mathrm{mr} / \mathrm{hr}$

B. Dose Rates 50-feet above Core Center

1. Unlimited Access: $2 \frac{1}{2} \mathrm{mr} / \mathrm{hr}$

II. Shutdown Following 17-days of 400 MW Operation

A. Sodium-24 Activity (1-day after shutdown)

1. Dose Rate 3-feet above Rotating Shield: $2 \frac{1}{2} \mathrm{mr} / \mathrm{hr}$

B. Stuck-Fuel Activity (1-day after shutdown)

1. Dose Rate 3-feet above Rotating Shield: $.100 \mathrm{mr} / \mathrm{hr}$

c. Surface of Fuel Handling Machine

1. Dose Rate from I element

$100 \mathrm{mr} / \mathrm{hr}$

(1-day after shutdown) 
The shield criteria for full power operation were based on an objective of allowing unlimited personnel access, i.e. $2 \frac{1}{2} \mathrm{mr} / \mathrm{hr}$, to the areas directly above the FFTF. An alternative criterion of restricted access, i.e. $100 \mathrm{mr} / \mathrm{hr}$, will be considered if the resulting shielding requirements appeared excessive. However, in this event, assurance would be required that the radiation levels outside the facility, i.e. 50-feet above the fueled core, be less than $2 \frac{1}{2} \mathrm{mr} / \mathrm{hr}$.

The principal problem in meeting the above full power shield criteria is attenuation of the fast neutrons that leak from the reactor core. The depth of the sodium pool is more than adequate to attenuate the primary gamma rays produced in the fueled core.

The shield criteria for shutdown at 24-hours following completion of a 17-day full power run involve 3 separate problems. The first problem is the dose rate resulting from radioactive decay of the Na-24 inventory in the sodium pool. The second problem is the dose rate resulting from the fission product activity in a single fuel element which is assumed to be stuck mechanically at a location just below the rotating shield. The analysis, to be described later, will show that the second of these two problems controls the minimum thickness of the top rotating shield. The third problem involves determining the required lead thickness about a fuel handling machine containing one "hot" fuel element. Sufficient shielding is to be provided so that the surface dose rate is less than $100 \mathrm{mr} / \mathrm{hr}$ at one-day following shutdown. III. ANAIYSIS

The analysis was performed with a number of radiation analysis computer codes on analytical representations of the physical system. A description follows of the computer codes and models used as well as the radiation source terms and nuclear data.

A. COMPUIER CODES

The computer codes used in this preliminary analysis include the DSN/DTK neutron transport codes, the QAD-P5 point kernel code, the FPIC code, and the ACT-II code. 
1. The DSN/DTK Codes (4)

The DSN and DTK codes are one-dimensional neutron transport codes. The DTK code was used in criticality calculations to define the neutron leakage spectrum in the axial and radial directions as well as the fast neutron distribution in the radial direction. Computation difficulties encountered in defining the axial neutron distributions required use of the DSN code in surface source calculations. Both 54 and 58 approximations were used in these calculations.

2. The QAD-P5 Code (5)

The QAD-P5 code uses a point kernel ray tracing approach for predicting neutron and gamma distributions and accounts for forward scattering by use of polynominal buildup factors. Flux, dose rate, and heating rate data are calculated at specified receiver points resulting from source points distributed in a threedimensional array for as many as 20 discrete energy groups .

This code was used to calculate the primary and secondary gamma distributions for the full power case as well as sodium decay gamma and fission product decay gamma distributions for the shutdown case. In addition, full power neutron distributions were calculated for comparison with the neutron transport predictions.

\section{The FPIC Code (6)}

FPIC is a fission product inventory code that calculates the buildup and decay of fission product activity. This code was used only to define the normalized time variation of fission product activity since its library is restricted to U-235 fission products. The actual source strength at 1-day following shutdown from a 17day run was obtained from Reference 7. 
4. The ACT-II Code

ACT-II is a code that predicts the buildup and decay of neutron induced activity for specified irradiation cycles. This code was used to predict the neutron induced activity levels anticipated for the process piping located in the pipe chase.

B. ANALYTICAL MODEL

The analytical model used in these shielding analyses is shown in Figure 2. This model was devised to represent the proposed arrangement for the FFTF. (2) The homogenized compositions for the different material zones are given in Table II.

Any deviation from this model imposed by specific problems will be identified when the results are presented. The required lead thickness about the fuel handing machine, for example, required placement of a lead cylinder about a line source located below the rotating shield. Moreover, the axial and radial traverses for radiation distributions will show a sketch of the corresponding analytical model.

\section{RADIATION SOURCE TERMS}

The required source terms include those for primary gamma rays, secondary gamma rays, fission product gamma rays, and radioactive decay gamma rays as well as fission neutrons.

\section{Primary Gamma Sources}

Primary gamma rays are those produced in the reactor core during full power operation. They usually include prompt fission gammas, fission product decay gammas, core capture gammas, and inelastic scattering gammas. However, for these studies, careful preparation of primary gamma source terms was not required since they have negligible contributions to the dose rates above the top rotating shield. To establish this point and to determine the gamma ray radial distribution at the core midplane, the primary gamma source terms developed for the NERVA reactor were used. These are given in Table III. Although developed for a U-235 system, these NERVA source term magnitude and spectra should be on the same order of those that might 





TABIE II

Compositions for the Material Zones

\begin{tabular}{|c|c|c|c|c|c|c|c|c|c|}
\hline \multirow[b]{2}{*}{ Region } & \multicolumn{9}{|c|}{ Element Density $(\mathrm{gm} / \mathrm{cc})$} \\
\hline & $\mathrm{Pu}$ & 0 & $\mathrm{Na}$ & $\mathrm{Ni}$ & 1 & $\mathrm{Fe}$ & $\mathrm{Cr}$ & c & $\mathrm{Pb}$ \\
\hline $\begin{array}{l}\text { Core } \\
\text { (Fission product) }\end{array}$ & 0.5567 & 0.0744 & 0.3884 & 0.3453 & $i$ & 3.194 & .777 & & \\
\hline (collector region) & & & 0.5438 & 0.254 & & $2 \cdot 348$ & 0.571 & & \\
\hline Sodium Pool \#I & & & 0.8629 & 0.01438 & & 0.1331 & 0.03238 & & \\
\hline Baffle & & & 0.8629 & 0.02876 & & 0.2662 & 0.06474 & & \\
\hline Sodium Pool \#2 & & & 0.8629 & 0.02876 & & 0.2662 & 0.06474 & & \\
\hline $\begin{array}{l}\text { Gaseous Helium } \\
\text { Region }\end{array}$ & & & 0.1099 & 0.02876 & & 0.2662 & 0.06474 & & \\
\hline Reactor Top Shield & & & 0.1099 & 0.02876 & s & 0.2662 & 0.06474 & 1.51 & \\
\hline Process Pipe Chase & & & 0.1099 & 0.02876 & 1 & 0.2662 & 0.06474 & & \\
\hline Process Shield & & & & 0.02876 & 1 & 0.2662 & 0.06474 & 1.51. & \\
\hline Rotating Shield & & & & 0.6336 & & 5.861 & 1.426 & & \\
\hline $\begin{array}{l}\text { Lead Personnel } \\
\text { Shield }\end{array}$ & & & & & & & & & 11.35 \\
\hline Pressure Vessel & & & & 0.6336 & & 5.861 & 1.426 & & \\
\hline Radial Reflector & & & 0.1744 & 4.856 & & 0.6744 & 1.214 & & \\
\hline Graphite Shield & & & & & & & & 1.8 & \\
\hline
\end{tabular}


TABLE III

Representative Primary Gamma Source Terms

\begin{tabular}{|c|c|c|}
\hline $\begin{array}{c}\text { Energy } \\
\text { Group }\end{array}$ & $\begin{array}{c}\text { Energy } \\
\text { Range (Mev) }\end{array}$ & $\begin{array}{c}\text { Source Strength } \\
\text { (Mev/Watt - sec) }\end{array}$ \\
\hline 1 & $7.0-8.0$ & $7.365 \times 10^{8}$ \\
2 & $6.0-7.0$ & $4.26 \times 10^{9}$ \\
3 & $5.0-6.0$ & $7.91 \times 10^{9}$ \\
4 & $4.0-5.0$ & $2.14 \times 10^{10}$ \\
5 & $3.0-4.0$ & $4.60 \times 10^{10}$ \\
6 & $2.6-3.0$ & $2.67 \times 10^{10}$ \\
7 & $2.2-2.6$ & $3.58 \times 10^{10}$ \\
8 & $1.8-2.2$ & $4.56 \times 10^{10}$ \\
9 & $1.35-1.8$ & $6.30 \times 10^{10}$ \\
10 & $0.90-1.35$ & $8.61 \times 10^{10}$ \\
11 & $0.40-0.90$ & $11.48 \times 10^{10}$ \\
12 & $0.26-0.40$ & $5.36 \times 10^{10}$ \\
\hline TOTAI & & $50.59 \times 10^{10}$ \\
\hline
\end{tabular}


be developed specifically for FFTF. These sources were given an axial and radial distribution that matches the fission density distribution.

2. Secondary Camma Sources

Secondary gamma sources are those produced by neutron capture during full power operation in regions external to the reactor core. For dose points located above the top rotating shield, the principle secondary sources are the sodium and steel regions above the reactor core. DTK leakage calculations indicate that $5 \times 10^{18}$ neutrons/ sec are absorbed in these regions with about an even split between the sodium and steel absorptions. Hence, using existing gamma yield data for neutron absorption, (9) the resulting full power secondary gamma sources are as given in Table IV.

These sources were given an axial distribution corresponding to the fast neutron distribution and a cosine radial distribution with $\mathrm{Po} / \mathrm{Pi}=0.5$. The azimuthal distribution was assumed to be flat.

\section{Fission Product Gamma Sources}

Fission product gamma sources are needed for treatment of the stuck-fuel problem as well as the specification for lead thickness in the fuel handling device. The source strength for this problem was taken from Reference 7 for the 1-day decay period and is shown in Table $\mathrm{V}$.

These source terms were used as a line source with a flat axial distribution. Its time variation, normalized to unity at 1-day, and as calculated with the FPIC code for a 17-day run, is shown in Figure 3.

\section{Radioactive Decay Source Terms}

The important radioactive decay source terms are those due to neutron capture in the sodium pool. Circulation of the radioactive sodium makes it a far more important source than decay of radioactive steel. 


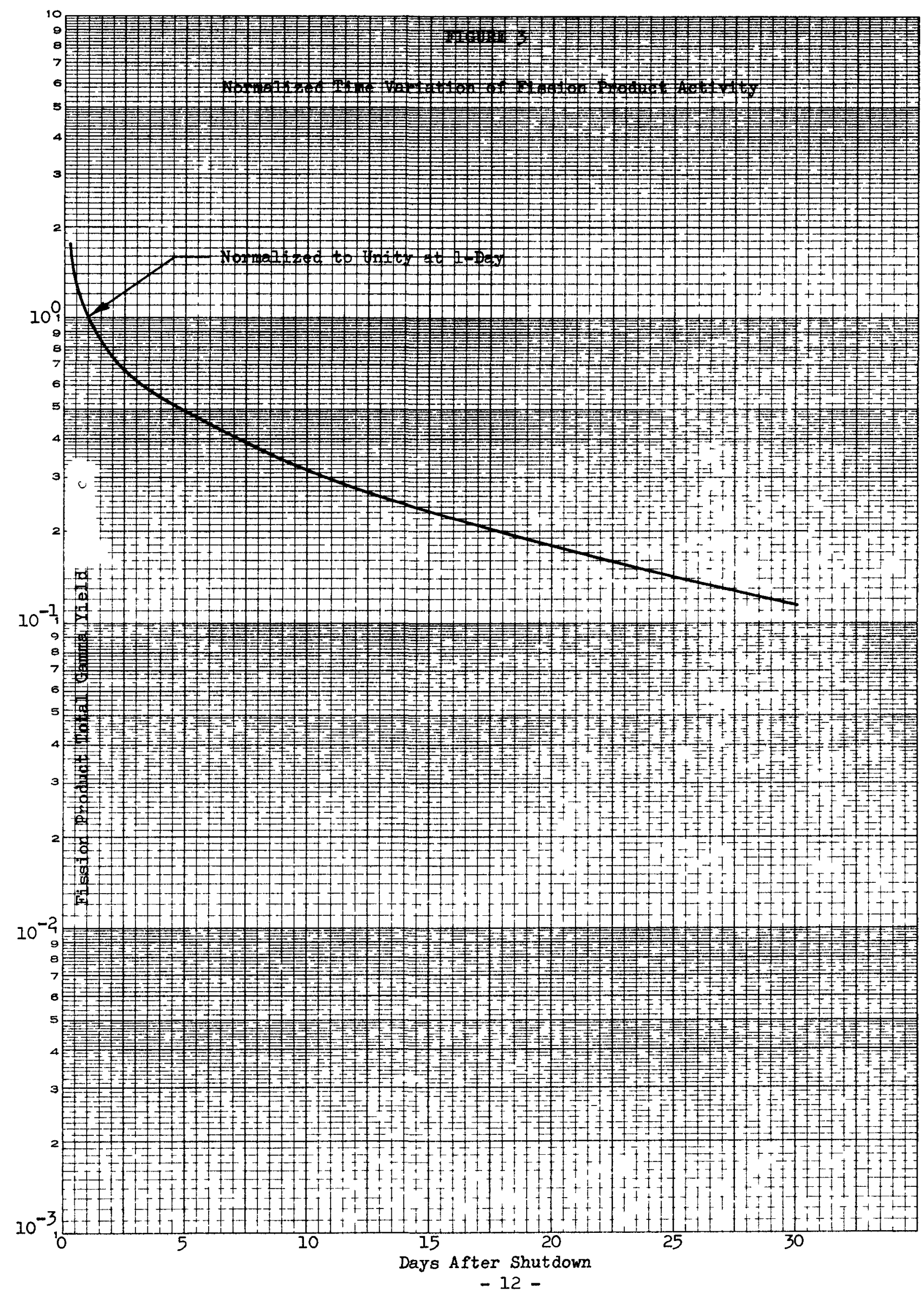


TABLE IV

\section{Secondary Gamma Source Terms}

\begin{tabular}{|c|c|c|c|}
\hline $\begin{array}{c}\text { Energy } \\
\text { Group }\end{array}$ & $\begin{array}{c}\text { Energy } \\
\text { Range }\end{array}$ & \multicolumn{2}{|c|}{ Source Strength (Mev/Sec) } \\
\cline { 3 - 4 } 1 & $7.0-8.0$ & & Sodium \\
2 & $6.0-7.0$ & $2.33 \times 10^{18}$ & $4.27 \times 10^{18}$ \\
3 & $5.0-6.0$ & $2.33 \times 10^{18}$ & $3.80 \times 10^{18}$ \\
4 & $4.0-5.0$ & $3.50 \times 10^{18}$ & $1.88 \times 10^{18}$ \\
5 & $3.0-4.0$ & $3.50 \times 10^{18}$ & $1.88 \times 10^{18}$ \\
6 & $2.6-3.0$ & $1.38 \times 10^{18}$ & $1.15 \times 10^{18}$ \\
7 & $2.2-2.6$ & & $1.15 \times 10^{18}$ \\
8 & $1.4-1.8$ & $6.76 \times 10^{18}$ & $1.69 \times 10^{18}$ \\
9 & $0.4-0.9$ & $2.40 \times 10^{18}$ & $2.25 \times 10^{18}$ \\
\hline TOTAL & & $22.20 \times 10^{18}$ & $0.94 \times 10^{18}$ \\
\hline
\end{tabular}


TABLE V

Fission Product Activity in a Single

Irradiated Fuel Element

\begin{tabular}{|c|c|c|}
\hline Group & $\begin{array}{c}\text { Average } \\
\text { Energy }\end{array}$ & $\begin{array}{c}\text { Source Term } \\
\text { (Mev/Sec) }\end{array}$ \\
\hline 1 & $2.9 \mathrm{Mev}$ & $2.2 \times 10^{15}$ \\
2 & $2.6 \mathrm{Mev}$ & $3.0 \times 10^{15}$ \\
3 & $2.2 \mathrm{Mev}$ & $1.5 \times 10^{15}$ \\
4 & $1.7 \mathrm{Mev}$ & $3.5 \times 10^{16}$ \\
5 & $1.3 \mathrm{Mev}$ & $9.0 \times 10^{15}$ \\
6 & $0.8 \mathrm{Mev}$ & $1.0 \times 10^{17}$ \\
7 & $0.4 \mathrm{Mev}$ & $2.0 \times 10^{16}$ \\
\hline TOTAL & & $17.07 \times 10^{16}$ \\
\hline
\end{tabular}


Prediction of the dose rates caused by decay of $\mathrm{Na}^{24}$ and $\mathrm{Na}^{22}$ require an accounting for all the neutrons that are absorbed in the sodium pool. In-core neutron absorption by the pool sodium is negligible relative to the out-of-core absorption. Hence the neutron leakage rates in both the top and bottom directions must be used to define the equilibrium $\mathrm{Na}^{24}$ activity. The neutrons that leak in the radial direction are absorbed principally in materials other than the sodium whereas about half of the axial leakage is absorbed in sodium.

Thus with top and bottom neutron leakage being about 1.0 $\times 10^{19}$ (neutrons/sec), the sodium absorptions producing $\mathrm{Na}^{24}$ will be about $5 \times 10^{18}$ (neutrons/sec). Since the total sodium inventory is about twice that contained in the reactor pool, the equilibrium sodium decay rate in the pool will be $2.5 \mathrm{x}$ $10^{18}$ (disintegrations/sec). Moreover, only a half of these will exist in the upper section of the pool. Hence the source terms used for $\mathrm{Na}^{24}$ as given in Table VI are based on an equilibrium rate of $1.25 \times 10^{18}$ (disintegrations/sec).

Also shown in Table VI is the source strength for radioactive decay of sodium -22. This isotope is produced by an $(n, 2 n)$ threshold reaction for neutrons with energy greater than $12.5 \mathrm{Mev}$.

The flux-weighted cross section for the $\mathrm{Na}^{23}(n, 2 \mathrm{n})$ $\mathrm{Na}^{22}$ reaction was found to be $7.5 \times 10^{-6}$ barns for the 3.0 to $20.0 \mathrm{Mev}$ group neutrons. The reaction rate for $\mathrm{Na}^{22}$ formation was obtained by determining the fraction of sodium absorptions occurring in the 3 to $20 \mathrm{Mev}$ group. Since the cross section for neutron absorption by sodium is $3.0 \times 10^{-2}$ barns in this energy group, the formation rate for $\mathrm{Na}^{22}$ can be determined and this was the method used to obtain the value shown in Table VI.

5. Fission Neutron Sources

Sources for fission neutrons were needed for the DSN/DTK calculations. The fission spectrum and fission yield reported by Hansen \& Roach ${ }^{(10)}$ for $\mathrm{Pu}^{239}$ were used in these calculations. In addition, the resulting multigroup fluxes are scaled to full 


\section{TABLE VI}

Source Terms for Sodium -24

In The Reactor Pool

\begin{tabular}{c|cc|c|}
\hline \multirow{2}{*}{ Group } & $\begin{array}{l}\text { Energy } \\
\text { Range }\end{array}$ & \multicolumn{2}{|c|}{ Source Terms (Mev/Sec) } \\
\cline { 2 - 4 } 1 & $2.6-3.0$ & $3.44 \times 10^{18}$ & Na-22 \\
\hline 2 & $1.4-1.8$ & $1.71 \times 10^{18}$ & $1.12 \times 10^{12}$ \\
3 & $0.9-1.4$ & & $1.12 \times 10^{12}$ \\
\hline TOTAL & & $5.15 \times 10^{18}$ & 1.24 \\
\hline
\end{tabular}


power values by normalizing total neutron flux at core center to $1.12 \times 10^{16}\left(\mathrm{n} / \mathrm{cm}^{2}-\mathrm{sec}\right)$.

\section{NUCLEAR DATA}

In analysis of radiation transport problems, the various nuclear interaction rates are defined by cross dection data. The various cross section used for determining the neutron and gamma distributions are described below.

\section{Neutron Cross Sections}

The 16-group neutron cross sections reported by Hansen and Roach $(10)$ were used in the DSN/DTK calculations. Neutron distributions predicted with the QAD-P5 code used 10-group carbon moments constants that were curve fitted to the data reported by Goldstein (11).

\section{Gamma Ray Cross Sections}

Camma Ray distribution calculations with the QAD-P5 code requires the use of total absorption coefficients $(12)$ and buildup factors ${ }^{13)}$. The buildup factors are needed to account for the fact that gamma rays are not absurbed in Compton scattering events. Rather, they undergo a change in direction and some degradation in energy with a substantial probability of returning to the initial direction still having a significant fraction of the incident energy. It is necessary, therefore, to increase the point kernel prediction of the uncollided flux by the buildup factor.

Both lead and aluminum dose buildup factors were used in the gamma ray calculations. The aluminum buildup factors were used for those configurations that have sodium or steel as the principal material nearest the receiver point. Lead buildup factors were used for those configurations that have lead shielding, such as the fuel handling machine. 
IV. $\underline{\text { RESULTS }}$

The analys is results are conveyed in this section. They include neutron and gamma ray distributions for both full power and shutdown conditions. The results are described relative to the problem objectives and shield criteria in order that preliminary selections can be made of shield materials and thicknesses. Moreover, sufficient detail is provided to allow assessment of alternative approaches as well as changes in shield criteria.

A. FULL POWER RADIATION DISTRIBUTIONS

The full power radiation distributions include radial and axial traverses through the reactor core center for such parameters as fast neutron flux, gamma ray dose rate, and gamma heating rates. These distributions are provided for various configurations of shields above the reactor core.

1. Radial Distributions

Full power fast neutron flux $\left(E_{n^{\prime}}>0.1\right.$ Mev $)$ is shown as a function of radius at the core midplane in Figure 4. These data were calculated with the DTK code in a cylindrical geometry with axial leakage represented by a $\mathrm{DB}^{2}$ term. The DTK flux values were scaled up for a total flux of $1.12 \times 10^{16} \mathrm{n} / \mathrm{cm}^{2}-\mathrm{sec}$ at core center.

These data will be useful for assessment of radiation damage problems in the metallic structures. Note that the Inconel reflector and stainless steel pressure vessel can achieve integrated exposures in excess of $1 \times 10^{21}$ (neutrons $/ \mathrm{cm}^{2}$ ).

Full power gamma ray dose rate is shown as a function of radius in Figure 5. The primary gamma data were calculated with the QAD-P5 code. The secondary gamma contribution, which was not calculated, is expected to be dominant for radii greater than $60-\mathrm{cm}$. The dotted curve shows this distribution as obtained from Reference 7 .

2. Axial Distributions

The axial distributions of fast neutron flux are shown in Figure 6 , as calculated with the DSN code, for various shield configurations using borated graphite. A 12-inch thick top rotating shield made of stainless steel is assumed for all cases. 


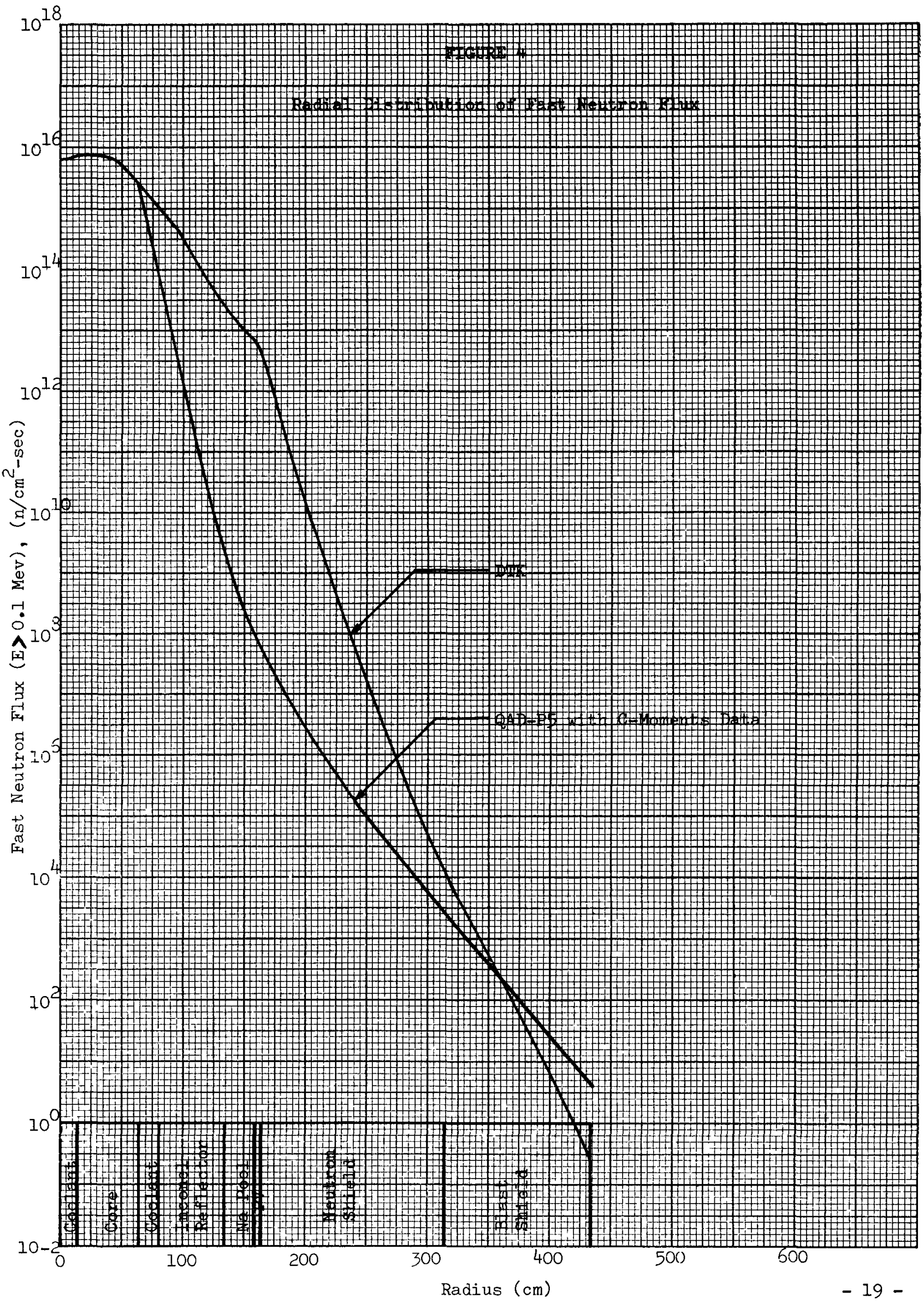









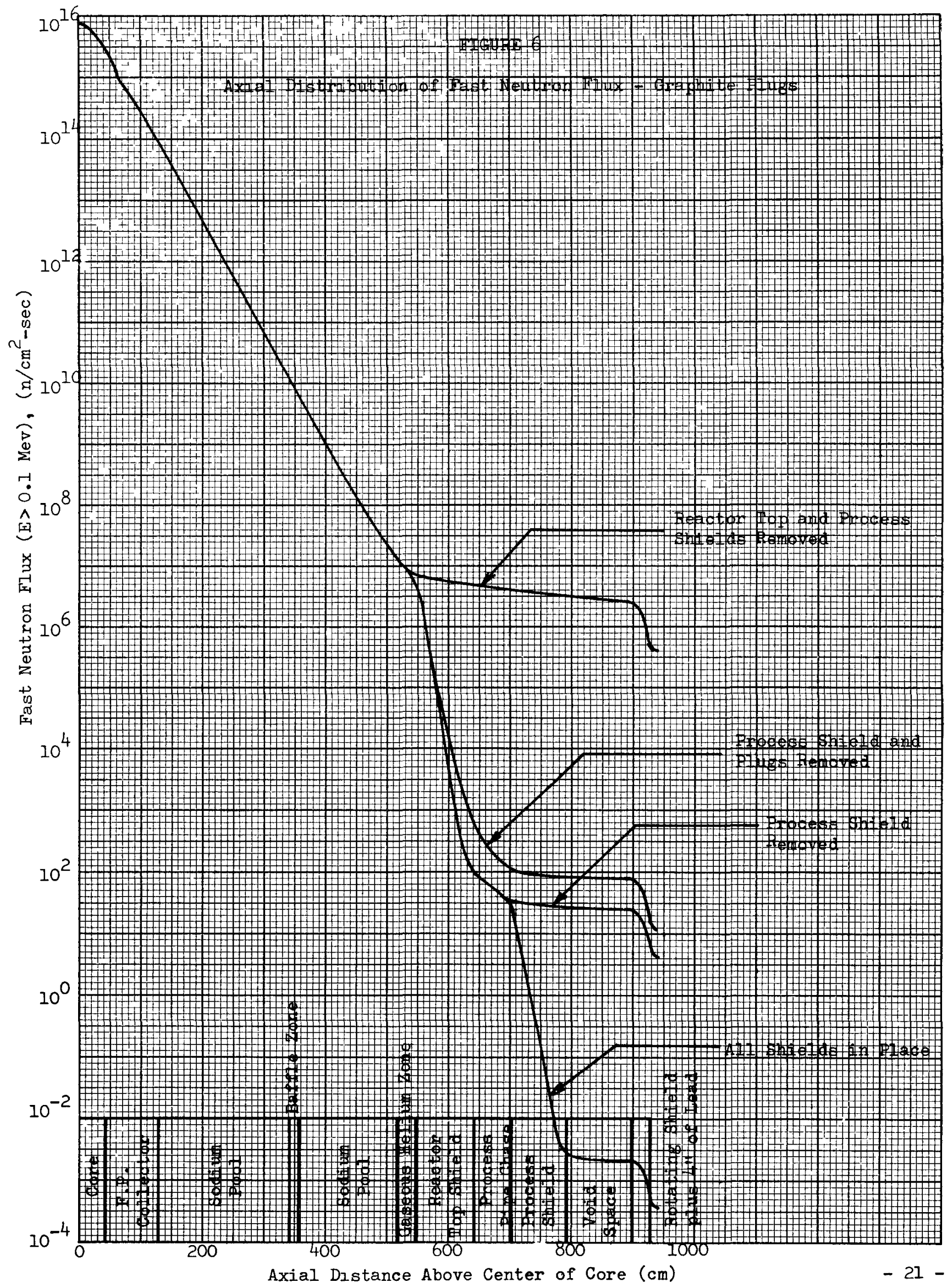


The criteria indicate that the dose rates must be less than either $2 \frac{1}{2}(\mathrm{mrem} / \mathrm{hr})$ or $100(\mathrm{mrem} / \mathrm{hr})$. The factor of 40 that separate these criteria is expected to be order of uncertainty in these deep penetration shielding calculations. Hence shield selections will be based on the more conservative criterion of $2 \frac{1}{2}(\mathrm{mrem} / \mathrm{hr})$.

The neutron flux that corresponds to this dose rate is dependent on the spectrum of the leakage neutrons. For this analysis, 25 (neutrons $/ \mathrm{cm}^{2}-\mathrm{sec}$ ) is taken as equivalent to the $2 \frac{1}{2}(\mathrm{mrem} / \mathrm{hr})$ specification.

Hence a fast neutron attenuation factor of about $2 \times 10^{4}$ will be required. This attenuation factor can be obtained by a number of alternative shield materials and material distributions. From Figure 6, a 36-inch thick borated graphite block for the reactor top shield appears to be adequate. Note that borated graphite shield plugs in the process tubes are not required, provided the space is filled by neutron scattering material such as sodium. If later analyses show neutron streaming to be a problem, then splitting the 36 -inch block in two sections can be considered. One section can be used at the reactor top shield and the other section at the process shield.

Figure 7 shows similar distributions wherein the borated graphite plug is replaced with a canned polyethelene plug. These data show that some reduction in shield thicknesses can be achieved by use of a more efficient shield material. However, the thickness specifications for a borated graphite shield do not appear excessive so that the polyethelene plug or even the borated graphite plug should be considered as a contingency item.

Figure 8 shows the fast neutron distributions predicted with the QAD-P5 code using carbon moments data. This calculation was performed for comparison purposes only. Note that the emergent neutron flux is about two decades higher than the corresponding value in Figure 6. Hence, although the available neutron moments data did not allow adequate treatment of this heterogeneous assembly, the differences tend to identify a relatively significant degree of uncertainty in prediction of fast neutron distributions. Therefore, 


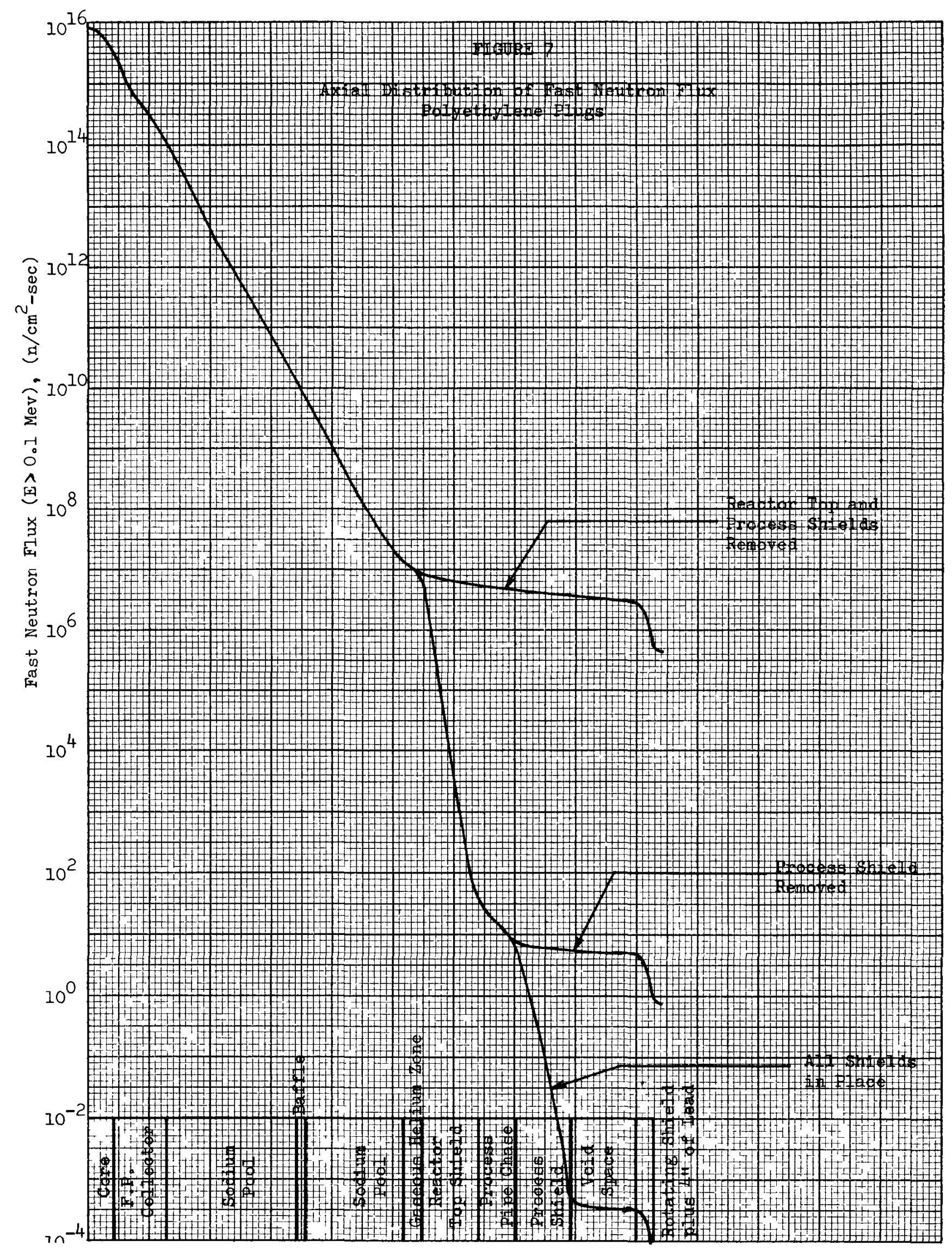




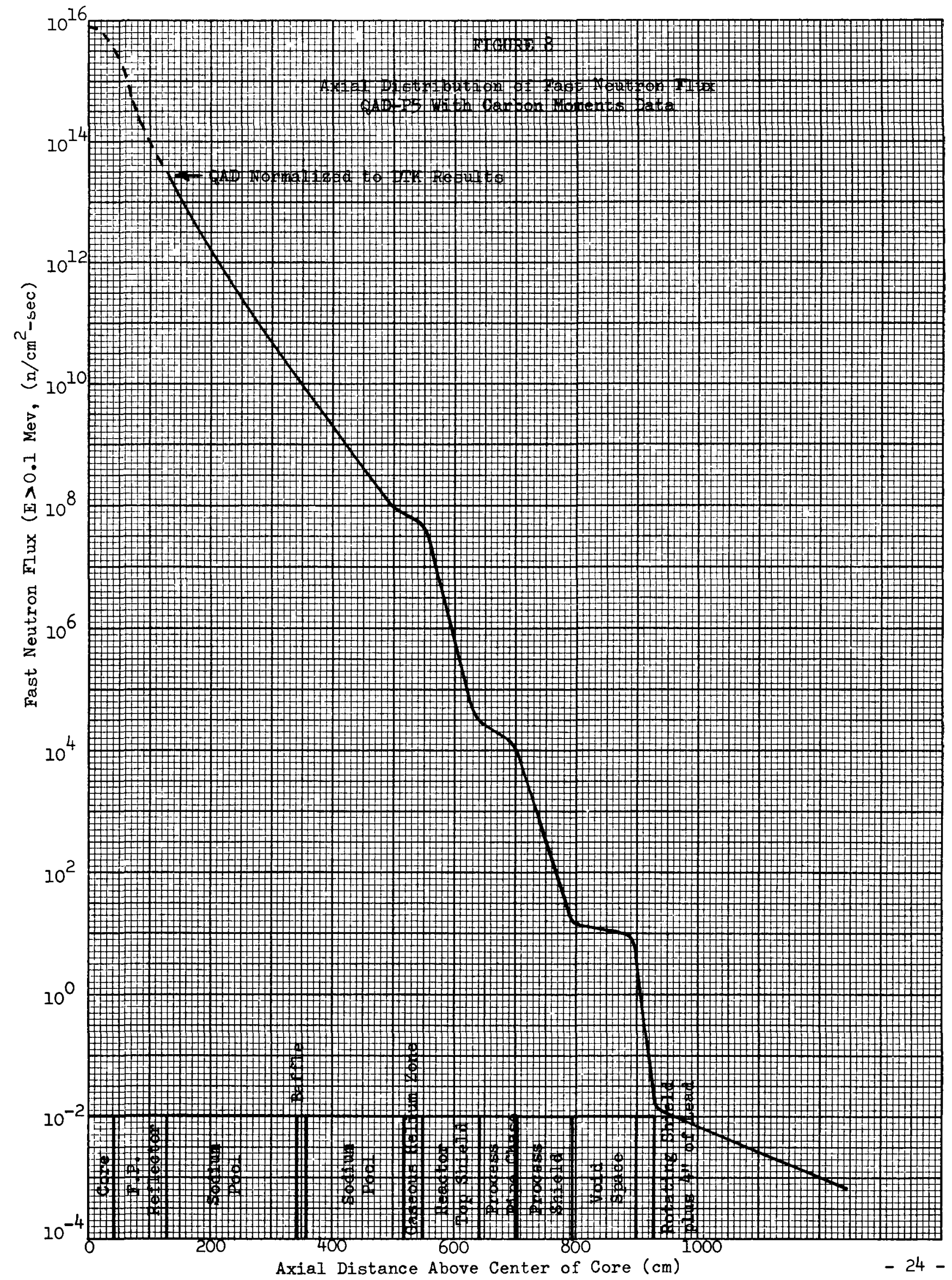


the use of shield plugs in the process tubes should be considered as a contingency item for prediction uncertainties.

The energy distributions of leakage neutrons are useful in assessment of the shielding problem as well as in interpreting the spatial distributions. Figure 9 shows the relative neutron spectra at three locations. These include a point just above the reactor core, a point just below the reactor top shield, and a point above the top rotating shield. The data were obtained from a combination of DTK and DSN neutron transport calculations.

Axial distributions of unshielded gamma dose rates are given in Figure 10. These curves provide a comprehensive survey of the gamma shielding problem. The data were generated with the QAD-P5 code using a model with the three shields removed.

It is evident from these curves that the primary gamma rays, i.e. those produced in the reactor core, are unimportant in terms of the dose rates above the reactor top shield. Moreover, the sodium and steel capture gamma rays contribute no more than $10(\mathrm{R} / \mathrm{hr})$ below the top rotating shield.

Thus, the gamma shielding requirement during full power operation is an attenuation factor of less than four decades. The 12-inch thick top rotating shield selected to meet the "stuck-fuel" incident provides about six decades of attenuation. Discussion of this selection is given in the next section.

\section{B. SHUTDOWN RADIATION DISTRIBUTIIONS}

Radiation distribution studies for the shutdown case include a number of independent problems. They include the "stuckfuel" problem, the radioactive sodium problem, the radioactive pipe chase problem, and the shielding required for the fuel handing machine.

\section{1. "Stuck-Fuel" Problem}

The "stuck-fuel" problem is defined as a fuel element being held just below the top rotating shield and requiring limited personnel access to the fuel handing machine directly 


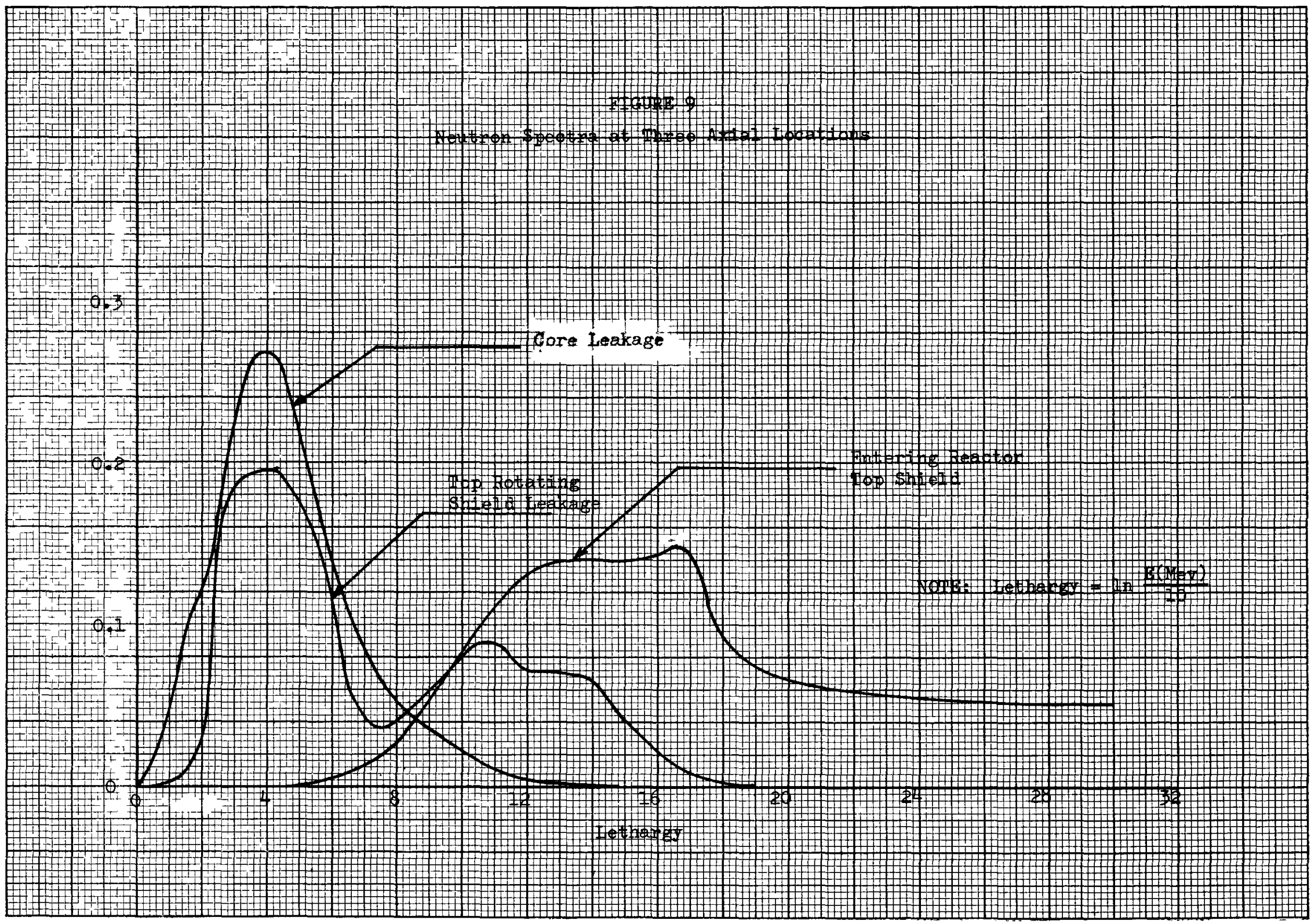


above the element. The QAD-P5 calculated gamma dose rates using lead buildup factors are shown in Figure 11.

To meet the criteria of $100(\mathrm{mr} / \mathrm{hr})$ at 3 -feet above the rotating shield, 4-inches of lead are needed in addition to the 12-inches of steel for the top rotating shield. However, the Iead section may be a portable section that is used only when required.

\section{Radioactive Sodium Problem}

The gamma dose rate distributions from decay of $\mathrm{Na}^{24}$ for both a homogeneously mixed pool and a baffled pool are shown in Figure 10. Note that these distributions are for the unshielded configuration.

Since the 12-inches of steel required for the "stuckfuel' problem provide an attenuation factor of about six decades, the dose rate contribution from $\mathrm{Na}^{24}$ decay will be well below the criterion of $2 \frac{1}{2}(\mathrm{mr} / \mathrm{hr})$. Hence, if the "stuckfuel" criterion is retained, then a sodium baffle in the pool will not be required. Moreover, since the ratio of the homogeneously mixed to the baffled dose rate is only a factor of three decades, use of about 6-inches of steel in the top rotating shield might be preferable to the use of a sodium baffle in the pool.

The dose rate contribution from the long lived $\mathrm{Na}^{22}$ activity does not appear to be significant. The saturated source strengths given in Section III-C show them to be more than six decades below the saturated $\mathrm{Na}^{24}$ activity.

3. Pipe Chase Shielding Requirement

Long term exposure ( $\sim 20$ yrs) of the pipe chase was considered as a potential source of neutron induced activity. An assessment of this problem was obtained by considering a l-1b sample of stainless steel 304. This sample was assumed to be irradiated for both 17-days and for 20-years at neutron flux levels that emerge from a 36-inch thick reactor top shield. 
The resulting dose rate 3 -feet from the sample as a function of time after exposure is given in Figure 12 as calculated by the ACT-II code.

Note that even with a four decade increase in the sample mass, the dose rates remain well below the $\mathrm{Na}^{24}$ decay activity. Hence this problem does not appear to be significant.

4. Fuel Handling Machine Shield Requirement

The fuel handling machine will have a single irradiated fuel element that must be shielded such that surface activity will be less than $100 \mathrm{mr} / \mathrm{hr}$. QAD-P5 calculations show that 10.6 inches of lead will be required to meet this criterion. The radial distribution of gamma dose rate is shown in Figure 13.

V. $\quad$ CONCLUSION

This survey of the FFTF shielding problems has identified the dominant contributors to the radiation environment. Moreover, on the basis of these studies, preliminary selections are made for the various FFTF radiation shielas.

The top rotating shield will require 12 -inches of stainless steel and 4-inches of lead; the lead section may be portable and used only when required to resolve a "stuck-fuel" problem.

The reactor top shield and process shield will require a total thickness of 39-inches of borated graphite. The use of shield plugs in the process tubes, whether borated graphite or canned polyethelene, should be considered for use as a contingency item to cover prediction uncertainties.

The fuel handling machine will require 10.6 inches of lead shielding. 
FIGURE 10

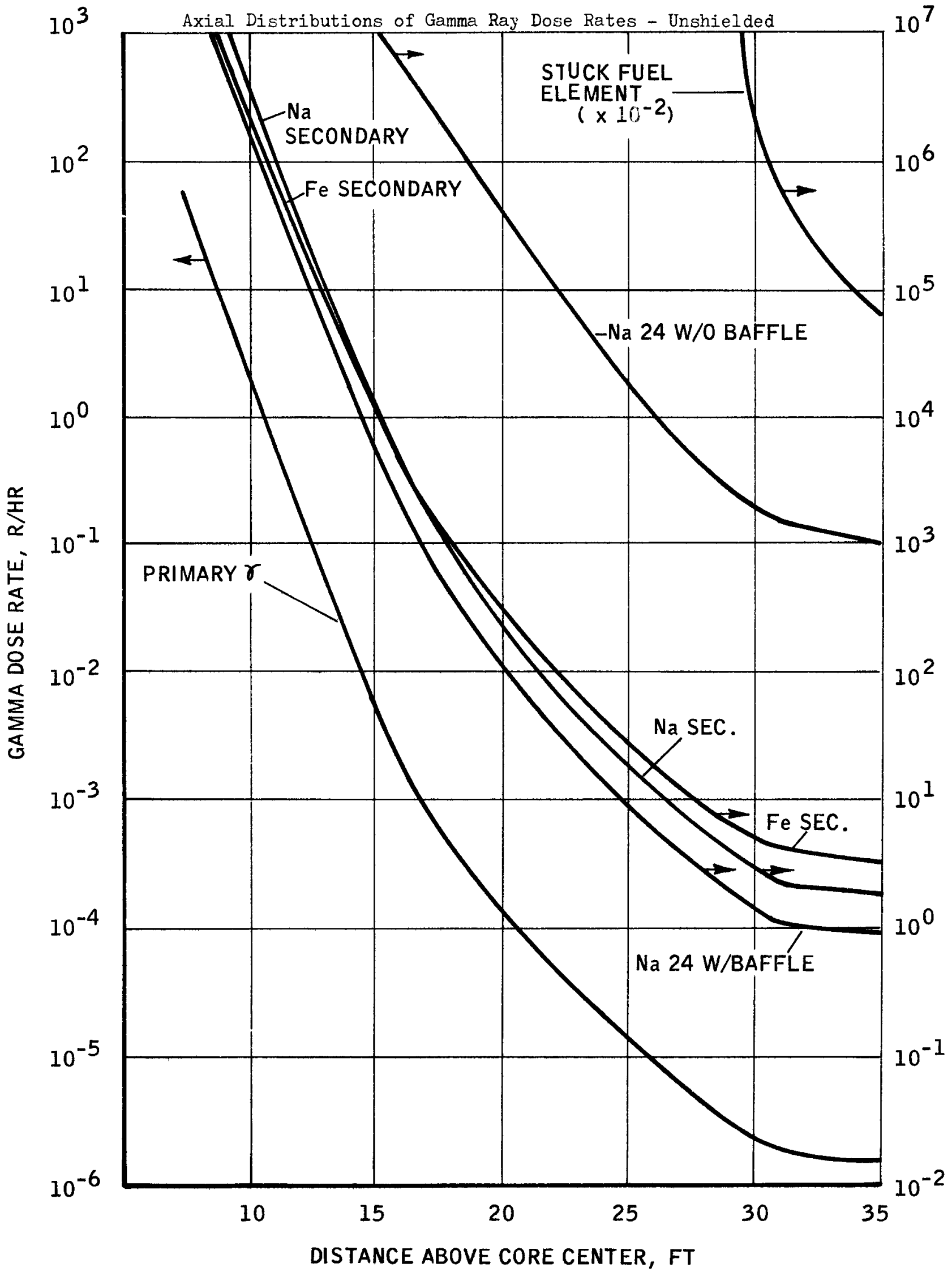




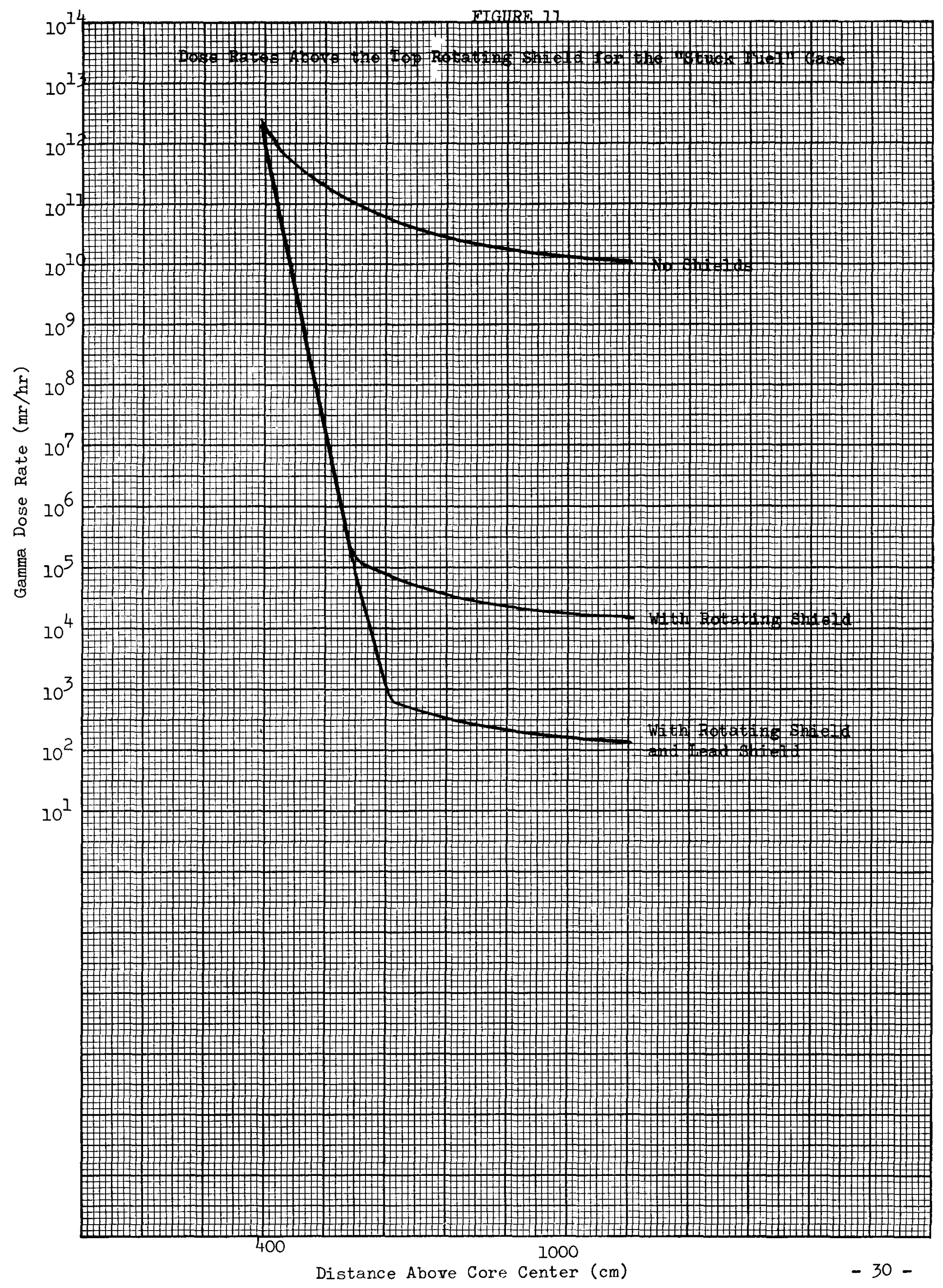




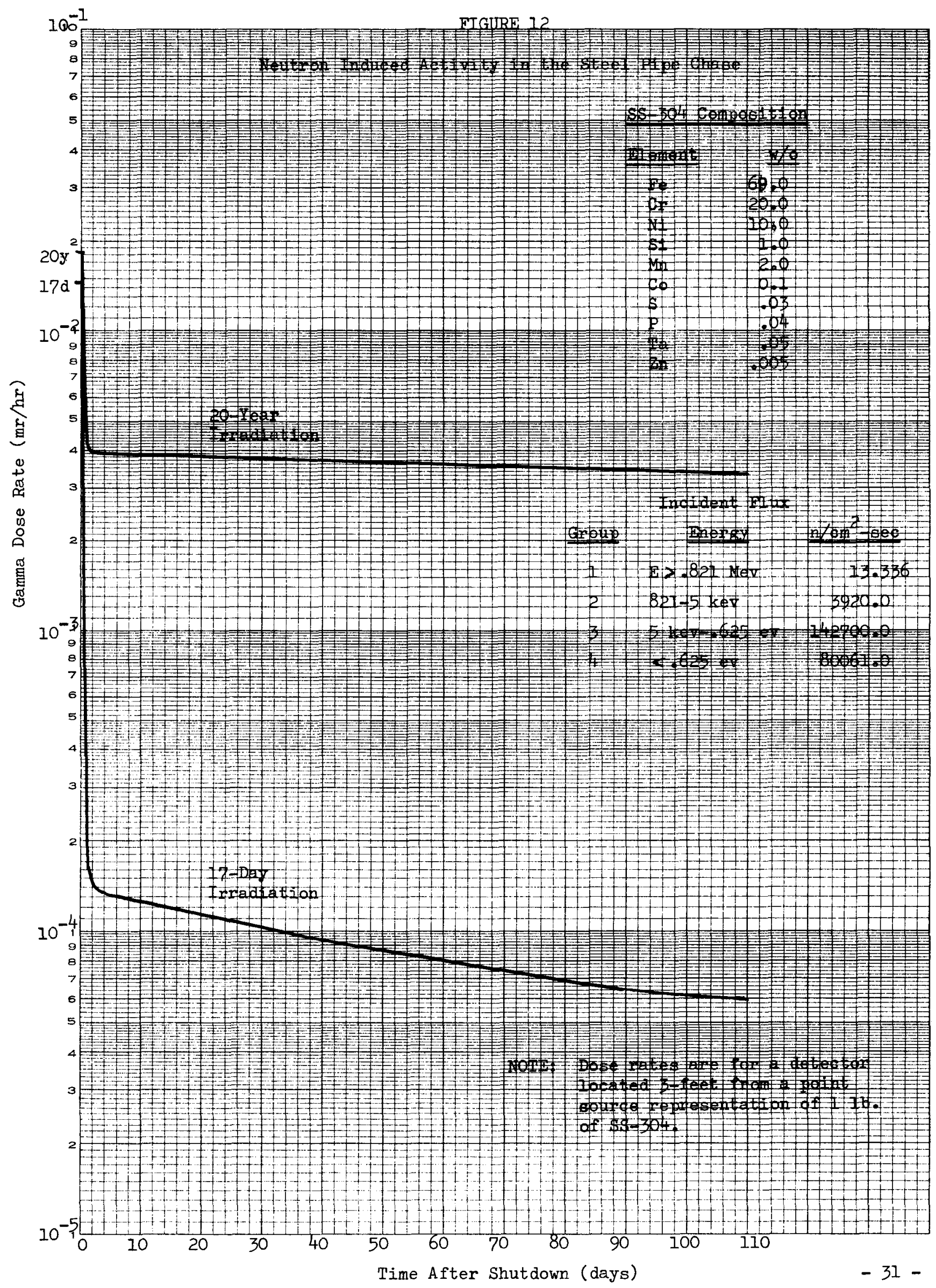




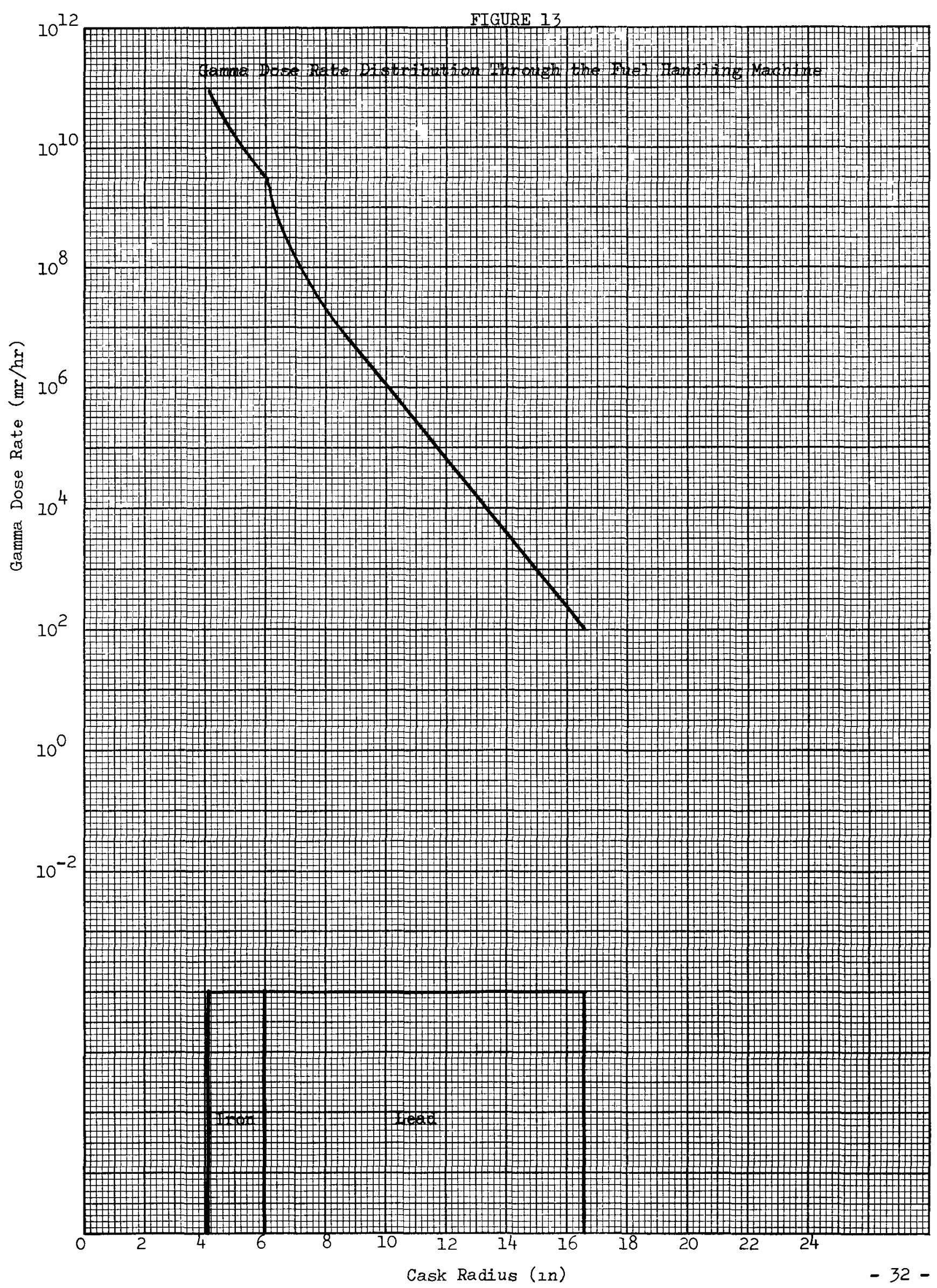

